\title{
Implementasi Algoritma Djikstra untuk Menentukan Lokasi dan Jarak Tempuh Terpendek Bank Syariah di Samarinda
}

\author{
Yusuf Arif Setiawan ${ }^{1 *}$, Windu Gata ${ }^{2}$, Sidik $^{3}$, Fariszal Nova Arviantino ${ }^{4}$ \\ 1,2,3,4 STMIK Nusa Mandiri \\ *14002635@nusamandiri.ac.id
}

\begin{abstract}
Islamic banks are the main preference for some adherents of the Islamic religion when transacting or saving their money. Although the concept of Islamic banking has been around for a long time in Indonesia, until now the existence of Islamic banks has not been widely known to the public. This is understandable because the number of Islamic banks can still be counted on the fingers. Another thing, the location of Islamic banks also rarely occupies the protocol road, making it difficult to find. Therefore, information on the closest route that can be passed to the Sharia Bank office is needed. To determine the closest route, the algorithm commonly used for finding the shortest route is Dijkstra's Algorithm. With information on the closest route from the market to the Sharia Bank office, when in an urgent situation, customers no longer have trouble finding the closest route to the Sharia Bank office.
\end{abstract}

Keywords: Dijkstra's Algorithm, Islamic Bank, Shortest Route

\begin{abstract}
Abstrak
Bank Syariah menjadi prefrensi utama bagi sebagian penganut agama Islam saat bertransaksi atau menyimpan uangnya. Walaupun sudah lama konsep Bank Syariah ada di Indonesia, namun hingga saat ini keberadaan Bank Syariah belum banyak diketahui masyarakat. Hal ini dapat dipahami karena jumlah Bank Syariah masih dapat dihitung dengan jari. Hal lainnya, lokasi Bank Syariah juga jarang menempati jalan protokol, sehingga sulit ditemukan. Oleh karena itu dibutuhkan informasi rute terdekat yang dapat dilalui menuju kantor Bank Syariah. Untuk penentuan rute terdekat digunakan Algoritma yang biasa dipakai untuk pencarian rute terpendek yaitu Algoritma Dijkstra. Dengan adanya informasi rute terdekat dari pasar menuju kantor Bank Syariah, maka ketika dalam keadaan mendesak nasabah tidak lagi kesulitan mencari jalur yang paling dekat menuju kantor Bank Syariah.
\end{abstract}

Kata kunci: Algoritma Dijkstra, Bank Syariah, Rute Terpendek

\section{Pendahuluan}

Bank syariah adalah suatu system perbankan yang dikembangkan berdasarkan prinsip syariah. Adanya perbankan syariah di Indonesia merupakan suatu wujud penerapan ekonomi Islam yang tentu dibutuhkan oleh masyarakat muslim dalam hal keperluan jasa perbankan. Namun demikian, masih terdapat kendala yang menghambat mereka untuk berpaling kepada bank syariah ini. Beberapa alasan yang mendasari adalah sulitnya mencari lokasi kantor layanan Bank Syariah yang ada. Bila diperhatikan lokasi Bank Syariah jarang yang terletak di jalan protokol, atau dekat pusat keramaian sehingga ketika nasabah atau calon nasabah akan mendatangi maka kesulitan untuk menjangkau.
Dengan meningkatnya minat masyarakat untuk menabung di Bank Syariah, maka informasi keberadaan Bank Syariah hendaknya mudah didapat. Secara karakteristik kantor Bank biasanya terletak didekat pusat bisnis seperti pasar. Lokasi yang berhubungan dengan pusat bisnis akan memudahkan mobilisasi masyarakat dalam melakukan usahanya sekaligus bertransaksi diperbankan. Sayangnya keberadaan Bank Syariah dipusat keramaian kadang tidak terdeteksi karena terlalu padatnya lalu lintas, atau tersembunyi oleh rimbunnya parkir kendaraan para nasabahnya. Kantor Bank Syariah sendiri rata rata terletak di sebuah ruko, sehingga sudah dikenali. Maka untuk membantu para nasabah dan walk in costumer 
menemukan lokasi kantor Bank Syariah tertentu, dibuat informasi yang dapat dimanfaatkan untuk mencari rute terdekat menuju kantor Bank Syariah tersebut.

Salah satu metode yang sering digunakan untuk mencari rute terdekat adalah dengan menggunakan Algoritma Dijkstra. Dengan algoritma ini dapat dicari jalur dengan jumlah bobot yang paling minimum antara titik yang satu ke titik lainnya[1]. Jarak dan rute terdekat yang dihasilkan dalam Algoritma Dijsktra menggunakan parameter tempat asal dan tempat tujuan[2]. Pada penelitian ini Algoritma Dijsktra digunakan untuk menentukan rute terpendek dari pasar sebagai parameter tempat asal ke Bank Syariah sebagai parameter tempat tujuan. Untuk proses perhitungan jarak dan rute terdekat, dilakukan melalui perhitungan jarak tiap persimpangan jalan yang dilalui oleh pasar dan Bank Syariah di Samarinda sehingga didapatkan jalur terpendek yang dapat dilalui.

Graf merupakan representasi dari gambaran hubungan yang melibatkan antara satu objek dengan objek yang lain, dimana objek diwakili oleh simpul (node), yang saling terhubung melalui garis yang disebut juga dengan sisi (edge)[3]. Contoh penggunaan graf seperti penggambaran struktur organisasi, arus lalu lintas, peta, sistem penjualan dan sebagainya. Berdasarkan orientasi arah pada sisi maka graf dapat dibedakan mejadi dua jenis yaitu graf berarah dan graf tidak berarah. Simpul pada graf berarah dihubungkan oleh sisi yang memiliki orientasi arah. Dimana graf berarah $(u, v)$ berbeda dengan graf berarah $(v, u)$. Sedangkan pada graf tidak berarah, sisi yang menghubungakan antar simpul tidak memiliki orientasi arah, sehingga urutan pasangan simpul dapat diabaikan [4].

Lintang dan bujur yang ditampilkan pada Google Maps merupakan dasar dari sistem koordinat geografis yang digunakan untuk menunjukan suatu titik di bumi [5]. Jarak antara dua titik kordinat digambarkan sebagai bobot sisi di dalam graf pada penelitian ini.

Masalah lintasan terpendek merupakan salah satu masalah kombinatorial yang paling mendasar dan terkenal yang sering muncul di berbagai bidang ilmu seperti aplikasi jaringan jalan, transportasi dan aplikasi lainnya[6]. Menetukan lintasan terpendek berarti menentukan lintasan dengan jarak paling minimum yang dibutuhkan dari tempat asal untuk sampai ke tempat tujuan. Untuk menyelesaikan masalah pencarian lintasan atau rute terpendek diperkenalkan algoritma untuk pencarian rute terpendek salah satunya yaitu Algoritma Dijsktra.

Algoritma merupakan kumpulan perintah yang logis dan sistematis yang diterjemahkan secara bertahap dari awal hingga akhir sehingga dapat menyelesaikan suatu masalah[7]. Terdapat tiga cara dalam penulisan Algoritma yaitu:

1. Kalimat deskriptif, dengan cara menuliskan instruksi-instruksi yang harus dilaksanakan dalam bentuk untaian kalimat deskriptif.

2. Flowchart (diagram alir), penulisan algoritma dengan menggunakan notasi grafis, yang memperlihatkan urutan atau langkah-langkah dari suatu program dan hubungan antar proses beserta pernyataannya.

3. Psuedocode, yang berisi deskripsi dari algoritma pemrograman komputer yang menggunakan struktur sederhana dari beberapa bahasa pemrograman tetapi bahasa tersebut hanya ditujukan agar dapat dibaca manusia [8]

Penulisan algoritma harus mengikuti langkah-langkah yang benar agar mudah dibaca dan dipahami. Walaupun setiap orang mempunyai aturan dan penulisan algoritma masing-masing yang berbeda, sebaiknya tulisan algoritma yang dibuat mempunyai korelasi dengan tulisan bahasa pemograman yang sudah umum digunakan.

Algoritma Dijsktra populer digunakan untuk memecahkan masalah yang berhubungan dengan pencarian lintasan terpendek. Metode pencarian lintasan terpendek menggunakan Algoritma Dijsktra dapat digunakan apabila jarak antara sebuah simpul ke simpul lain dalam graf memiliki bobot positif, jika terdapat bobot negatif maka penyelesaian yang diberikan adalah infiniti (tak terhingga) [9]. Node atau simpul pada Algoritma Dijsktra digunakan karena dalam 
penentuan rute lintasan terpendek menggunakan graf berarah.

Langkah-langkah dasar dari Algoritma

Dijsktra adalah:

1. Dimulai dari node yang kita pilih sebagai node sumber (node awal), kemudian menganalisa graf untuk menentukan jalur terpendek antara node awal dengan semua node lain yang ada di dalam graf.

2. Algoritma kemudian menghitung jarak terpendek dari setiap node yang diketahui ke node awal. Node yang telah mempunyai jarak terpendek kemudian diberi label "visited" (telah dikunjungi) dan ditambahkan ke jalur

Proses dilanjutkan sampai semua node dalam graf sudah ditambahkan ke jalur. Sehingga kita mendapatkan jalur yang menghubungkan node awal ke semua node lain mengikuti jalur terpendek yang mungkin untuk mencapai semua node[6].

\section{Metoda Penelitian}

Metode yang digunakan untuk mengumpulkan data dalam penelitian ini adalah:

Melalui observasi dengan melakukan pengumpulan data Bank Syariah dan pusat bisnis / pasar di wilayah Samarinda.

Melalui studi pustaka dengan melihat hasil penelitian dan karya penulisan, baik itu dari buku-buku, jurnal-jurnal, studi literatur maupun dari internet, dengan tema yang sejenis, dengan tujuan untuk menghindari kesalahan yang pernah terjadi di penelitian sebelumnya.

\section{Hasil Penelitian}

Dalam penelitian ini, yang dianggap sebagai node (simpul) adalah persimpangan jalan, pusat bisnis / pasar, dan Bank Syariah, sedangkan jarak antar persimpangan dianggap sebagai sisi (edge) yang memiliki bobot. Data Bank Syariah, pusat bisnis / pasar dan persimpangan jalan di wilayah kota Samarinda ditunjukkan dalam tabel berikut:

Tabel 1. Daftar Nama Bank Syariah di Kota Samarinda

\begin{tabular}{cl}
\hline Simpul & Keterangan \\
\hline A & Bank Negara Indonesia Syariah \\
\hline
\end{tabular}

\begin{tabular}{cl}
\hline Simpul & Keterangan \\
\hline B & Bank Syariah Mandiri \\
C & Bank Rakyat Indonesia Syariah \\
D & Bank Muamalat Indonesia \\
\hline
\end{tabular}

Tabel 2. Daftar Pusat Bisnis di Kota Samarinda

\begin{tabular}{cl}
\hline Simpul & Keterangan \\
\hline $\mathrm{a}$ & Lembuswana Mall \\
$\mathrm{b}$ & Pasar Pagi \\
$\mathrm{c}$ & Pasar Segiri Samarinda \\
$\mathrm{d}$ & Plasa Mulia \\
$\mathrm{e}$ & Mal Mesra \\
\hline
\end{tabular}

Tabel 3. Daftar Nama dan Koordinat Persimpangan di Kota Samarinda

\begin{tabular}{|c|c|c|}
\hline Simpul & Keterangan & Koordinat \\
\hline 1 & $\begin{array}{l}\text { Perempatan } \\
\text { Lembusuana }\end{array}$ & $-0.47549,117.14629$ \\
\hline 2 & $\begin{array}{l}\text { Perempatan } \\
\text { Juanda }\end{array}$ & $-0.47255,117.13854$ \\
\hline 3 & $\begin{array}{l}\text { Perempatan } \\
\text { Suryanata }\end{array}$ & $-0.48459,117.12666$ \\
\hline 4 & $\begin{array}{l}\text { Pertigaan } \\
\text { Cendana }\end{array}$ & $-0.49814,117.12677$ \\
\hline 5 & $\begin{array}{l}\text { Pertigaan } \\
\text { Martadinata }\end{array}$ & $-0.50021,117.12735$ \\
\hline 6 & Pertigaan BTN & $-0.50084,117.13517$ \\
\hline 7 & $\begin{array}{l}\text { Pertigaan } \\
\text { Gunung } \\
\text { Kinibalu }\end{array}$ & $-0.50184,117.14108$ \\
\hline 8 & $\begin{array}{l}\text { Perempatan } \\
\text { Bank Kaltim }\end{array}$ & $-0.50121,117.14362$ \\
\hline 9 & $\begin{array}{l}\text { Pertigaan Mall } \\
\text { Mesra }\end{array}$ & $-0.50174,117.14694$ \\
\hline 10 & $\begin{array}{ll}\text { Pertigaan } & \text { Jl. } \\
\text { Abul Hasan } & \end{array}$ & $-0.49970,117.14778$ \\
\hline 11 & $\begin{array}{l}\text { Perempatan } \\
\text { Basuki Rahmat }\end{array}$ & $-0.49577,117.14970$ \\
\hline 12 & $\begin{array}{l}\text { Bundaran } \\
\text { Taman } \\
\text { Samarinda }\end{array}$ & $-0.49678,117.14395$ \\
\hline 13 & $\begin{array}{l}\text { Pertigaan Taman } \\
\text { Makam } \\
\text { Pahlawan }\end{array}$ & $-0.48960,117.14633$ \\
\hline 14 & $\begin{array}{l}\text { Pertigaan Agus } \\
\text { Salim }\end{array}$ & $-0.49307,117.15145$ \\
\hline 15 & $\begin{array}{l}\text { Simpangan Jalan } \\
\text { Gatot Subroto, } \\
\text { Gang Mesiid }\end{array}$ & $-0.48938,117.15336$ \\
\hline 16 & $\begin{array}{l}\text { Perempatan } \\
\text { Merak }\end{array}$ & $-0.47925,117.15475$ \\
\hline
\end{tabular}

Tabel 4. Data Jarak Antar Node

\begin{tabular}{cccccc}
\hline No. & Node & $\begin{array}{c}\text { Jarak } \\
(\mathbf{m})\end{array}$ & No. & Node & $\begin{array}{c}\text { Jarak } \\
(\mathbf{m})\end{array}$ \\
\hline 1 & a-2 & 30 & 15 & $8-10$ & 400 \\
2 & a-b & 350 & 16 & $9-11$ & 1200 \\
\hline
\end{tabular}




\begin{tabular}{lccccc}
\hline \multicolumn{5}{|c}{ METIK VOLUME. 5 NOMOR. 12021} \\
\hline No. & Node & $\begin{array}{l}\text { Jarak } \\
(\mathbf{m})\end{array}$ & No. & Node & $\begin{array}{c}\text { Jarak } \\
(\mathbf{m})\end{array}$ \\
\hline 3 & b-c & 1200 & 17 & $\begin{array}{c}16- \\
13\end{array}$ & 48 \\
& & & & 13 & 1400 \\
4 & c-1 & 700 & 18 & $10-$ & 14 \\
& & & & 12 & \\
5 & e-1 & 1100 & 19 & $14-$ & 190 \\
& & & & 16 & \\
6 & $1-3$ & 1300 & 20 & $14-$ & 140 \\
& & & & 15 & \\
7 & $2-6$ & 3600 & 21 & $14-$ & 50 \\
& & & & 11 & \\
8 & $4-3$ & 71 & 22 & A-4 & 400 \\
9 & $4-5$ & 550 & 23 & B-1 & 750 \\
10 & $4-8$ & 1900 & 24 & B-d & 850 \\
11 & $5-6$ & 1400 & 25 & C-13 & 34 \\
12 & $7-8$ & 700 & 26 & C-11 & 150 \\
13 & $7-9$ & 800 & 27 & D-12 & 200 \\
14 & d-7 & 25 & 28 & D-15 & 110 \\
\hline
\end{tabular}

Berdasarkan tabel-tabel di atas dapat dibentuk graf seperti di bawah ini.

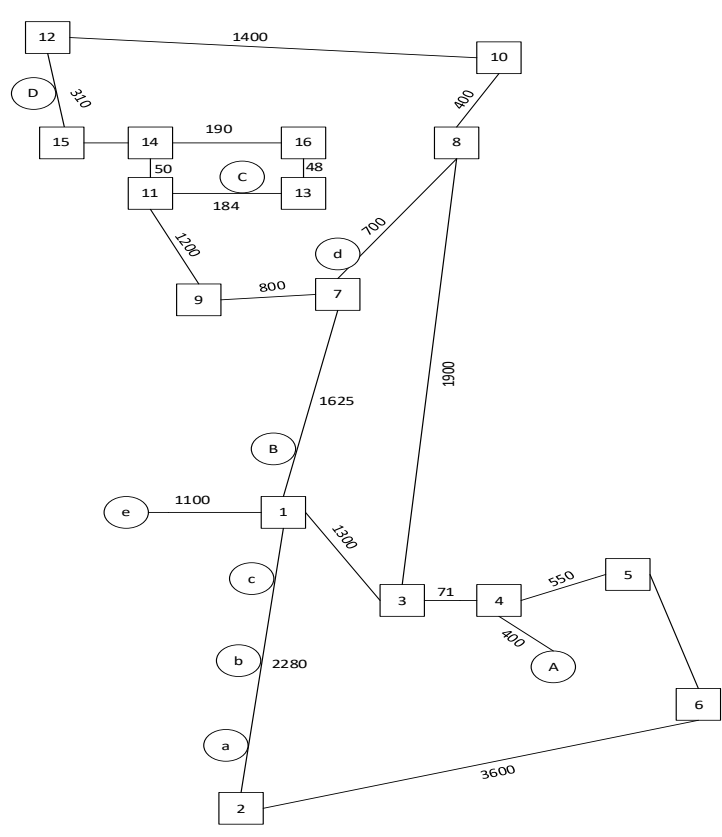

Gambar 1. Bank Syariah, Pusat Bisnis dan Persimpangan Jalan di Samarinda Kota

Sebagai node (simpul) awal adalah node a (Pusat Bisnis / Mall). Maka dengan menggunakan Algoritma Dijsktra dapat dihitung jarak terdekat node a ke masingmasing node-node lain di dalam graf. Simbol infinity dimaksudkan untuk representasi awal jarak node a ke node lain dalam graf[6].

Jarak yang terdekat dari node a ke node yang paling dekat yaitu node 1 dan 2 . Diketahui node 1,3,4,5, 6, dan 7 bersebelahan dengan node yang sudah ada di jalur karena terhubung langsung dengan node a dan 2 secara berurutan.

Perhitungan jarak terdekat dari node a ke node 6 melalui a-1-3-4-5-6 dengan total jarak $5566 \mathrm{~m}$ dan a-2-6 dengan total jarak 3630. Selanjutnya analisa node baru yang berdekatan dan bersebelahan dengan nodenode yang sudah ada di jalur yaitu node 8 . Diketahui jalur yang dapat dilalui dari node a ke node 8 yaitu a-1-3-8 dengan total jarak 5450, dan a-1-7-8 dengan total jarak 4575 . Analisa node baru yang berdekatan dan bersebelahan dengan node-node yang sudah ada di jalur yaitu node 9 dan 10. Jarak terdekat diperiksa dari node a ke node-node tersebut, ditambahkan pada jalur setelah dikunjungi. Selanjutnya dilakukan analisa node baru yang berdekatan dan bersebelahan dengan nodenode yang sudah ada di jalur yaitu node 11 , 12 13,14,15, dan 16. Jarak terdekat dari node a ke node-node yang sudah dikunjungi di tambahkan ke dalam jalur.

Tabel 5. Jarak Node Yang Sudah dikunnjungi

\begin{tabular}{cclccc}
\hline No. & $\begin{array}{c}\text { Jarak } \\
\text { terdekat } \\
\text { dari } \\
\text { node } \text { a }\end{array}$ & Status & No. & $\begin{array}{c}\text { Jarak } \\
\text { terdekat } \\
\text { dari } \\
\text { node } \text { a }\end{array}$ & Status \\
\hline a & 0 & visited & 9 & 4675 & visited \\
1 & 2250 & visited & 10 & 4975 & visited \\
2 & 30 & visited & 11 & 5829 & visited \\
3 & 3550 & visited & 12 & 6375 & visited \\
4 & 3621 & visited & 12 & 6013 & visited \\
5 & 4171 & visited & 13 & 5879 & visited \\
6 & 3630 & visited & 14 & 6019 & visited \\
7 & 3875 & visited & 15 & 6061 & visited \\
8 & 4575 & visited & 16 & 6013 & visited \\
\hline
\end{tabular}

Garis merah pada gambar menandai sisi yang termasuk dalam jalur terpendek. Garis merah sebagai jalur terpendek untuk mencapai node tertentu dalam grafik mulai dari node a seperti yang digambarkan di bawah: 


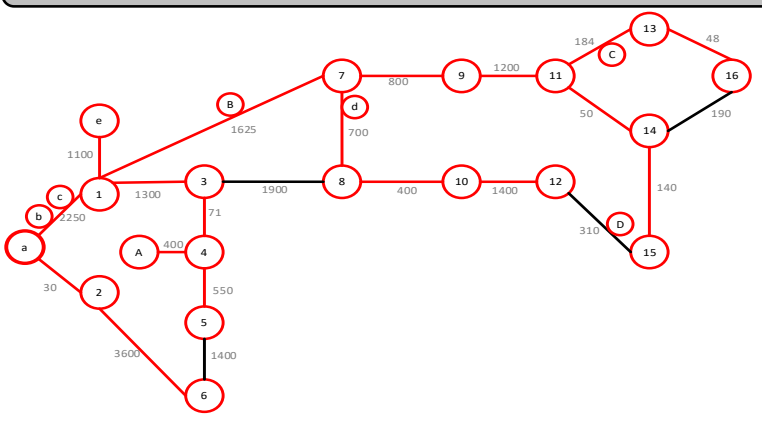

Gambar 2. Rute Terpendek dari Node a ke Node Lain di Dalam Graf

Setelah dilakukan perhitungan maka diperoleh jalur terpendek dari pasar atau pusat bisnis ke lokasi bank syariah di kota Samarinda sebagai berikut:

Tabel 12. Rute dari Pasar/ Pusat Bisnis dengan Lokasi Bank Syariah di Kota Samarinda

\begin{tabular}{lllll}
\hline Finish & \multicolumn{1}{c}{ A } & \multicolumn{1}{c}{ B } & \multicolumn{1}{c}{ C } & \multicolumn{1}{c}{ D } \\
& & & & \\
\hline a & a-1-3-4- & a-1-B & a-1-7- & a-1-7-9-11- \\
& A & & $9-11-C$ & $14-15-D$ \\
b & b-1-3-4- & b-1-B & b-1-7- & b-1-7-9-11- \\
& A & & $9-11-C$ & $14-15-D$ \\
c & c-1-3-4- & c-1-B & c-1-7- & c-1-7-9-11- \\
& A & & $9-11-C$ & $14-15-D$ \\
d & d-8-3-4- & d-7-B & d-7-9- & d-9-11-14- \\
& A & & $11-C$ & $15-D$ \\
e & e-1-3-4- & e-1-B & e-1-7- & e-1-7-9-11- \\
& A & & $9-11-C$ & $14-15-D$ \\
\hline
\end{tabular}

\section{Kesimpulan}

Penelitian ini mengimplementasikan algoritma Djikstra untuk mendapatkan dan menentukan rute terpendek menuju Bank Syariah dari titik awal node pusat bisnis atau pasar di Samarinda. Pengguna dapat memilih Bank Syariah tujuan dari lokasi pusat bisnis, dengan rute yang terdekat. Hasil penghitungan jarak terpendek dalam pencarian lokasi Bank Syariah juga dipengaruhi oleh gadget yang digunakan user. Pada penelitian ini menggunakan google maps di computer.

\section{Saran}

Dalam penelitian ini merupakan langkah awal dalam penerapan algoritma Djikstra untuk menentukan lokasi dan jarak tempuh terpendek bank syariah di samarinda. Untuk penelitian selanjutnya akan ditambahkan parameter lain yaitu jalan dua arah, agar hasil penelitian lebih dapat menggambarkan keadaan di lapangan yang sesungguhnya.

\section{Daftar Pustaka}

[1] M. S. Yusuf, H. M. Az-zahra, and D. H. Apriyanti, "Implementasi Algoritma Dijkstra Dalam Menemukan Jarak Terdekat Dari Lokasi Pengguna Ke Tanaman Yang Di Tuju Berbasis Android ( Studi Kasus di Kebun Raya Purwodadi )," J. Pengemb. Teknol. Inf. dan Ilmu Komput., vol. 1, no. 12, pp. 1779-1781, 2017.

[2] S. Andayani and E. W. Perwitasari, "Penentuan Rute Terpendek Pengambilan Sampah di Kota Merauke Menggunakan Algoritma Dijkstra," Aeminar Nas. Teknol. Inf. Komun. Terap., vol., no., pp. 164-170, 2014.

[3] A. Dey, R. Pradhan, A. Pal, and T. Pal, "A genetic algorithm for solving fuzzy shortest path problems with interval type2 fuzzy arc lengths," Malaysian $J$. Comput. Sci., vol. 31, no. 4, pp. 255-270, 2018, doi: 10.22452/mjcs.vol31no4.2.

[4] A. Noviriandini and M. Safitri, "Implementasi Algoritma Dijkstra Untuk Menentukan Jalur Terpendek Wilayah Pisangan Dan Kampus Nusa Mandiri Tangerang," J. Pilar Nusa Mandiri, vol. 13, no. 2, pp. 181-186, 2017.

[5] Y. Yulianto, R. Ramadiani, and A. H. Kridalaksana, "Penerapan Formula Haversine Pada Sistem Informasi Geografis Pencarian Jarak Terdekat Lokasi Lapangan Futsal," Inform. Mulawarman J. Ilm. Ilmu Komput., vol. 13, no. 1, p. 14, 2018, doi: 10.30872/jim.v13i1.1027.

[6] S. Broumi, A. Bakal, M. Talea, F. Smarandache, and L. Vladareanu, "Applying Dijkstra algorithm for solving neutrosophic shortest path problem," Int. Conf. Adv. Mechatron. Syst. ICAMechS, vol. 0, pp. 412-416, 2016, doi: 10.1109/ICAMechS.2016.7813483.

[7] G. G. Maulana, "PEMBELAJARAN DASAR ALGORITMA DAN PEMROGRAMAN MENGGUNAKAN EL-GORITMA BERBASIS WEB," $J$. Tek. Mesin, vol. 06, no. 2, pp. 69-73, 2017.

[8] A. M. Retta, A. Isroqmi, and T. D. Nopriyanti, "Pengaruh Penerapan 
Algoritma Terhadap Pembelajaran

Pemrograman Komputer," Indiktika J.

Inov. Pendidik. Mat., vol. 2, no. 2, p. 126, 2020, doi: 10.31851/indiktika.v2i2.4125.

[9] M. Muharrom, "Algoritma, Implementasi Dalam, Dijkstra Jalur, Penentuan Kasus, Studi Tempat, Jarak Terdekat, Kuliah,” Int. J. Bus. Intelegence, vol. 3, no. 1, pp. 25-30, 2020. 